\title{
Optimization and Modelling of the Wear in Piston Ring and Cylinder Liner Using Taguchi Method and Artificial Neural Networks
}

Idris cesur ( $\square$ icesur@subu.edu.tr)

Sakarya University of Applied Sciences

Aslan Çoban

Sakarya University of Applied Sciences

Beytullah Eren

Sakarya University: Sakarya Universitesi

Original Article

Keywords: Engine, wear, friction, Taguchi method, biodiesel, Artificial neural networks (ANNs)

Posted Date: March 1st, 2021

DOl: https://doi.org/10.21203/rs.3.rs-245705/v1

License: (c) (i) This work is licensed under a Creative Commons Attribution 4.0 International License.

Read Full License 


\title{
OPTIMIZATION AND MODELLING OF THE WEAR IN PISTON RING AND CYLINDER LINER USING TAGUCHI METHOD AND ARTIFICIAL NEURAL NETWORKS
}

\author{
İdris Cesur $^{*}$, Aslan ÇOBAN ${ }^{1}$, Beytullah EREN $^{2}$ \\ ${ }^{1}$ Department of Mechanical Engineering, Sakarya University of Applied Sciences, 54187, Sakarya, Turkey, \\ ${ }^{2}$ Department of Environment Engineering, Sakarya University, 54187, Sakarya, Turkey, \\ icesur@subu.edu.tr, vayhan@subu.edu.tr, acoban@subu.edu.tr, beren@sakarya.edu.tr
}

\begin{abstract}
Alternative energy sources are needed to meet the energy needs of the rapidly increasing population and developing industry and to increase the efficiency of the systems. In internal combustion engines, biodiesel is used as an alternative fuel for both being an alternative energy source and having a better efficiency compared to diesel fuel. Efficiency loss in the engines is largely due to friction and wear between the piston ring (PR) and the cylinder liner (CL). Different lubrication regimes in engines have substantial effects on wear and friction. In the present study, the effects of diesel and biodiesel (chicken oil methyl ester, COME) fuels on friction and wear in different loads (40-60-80-100 N) and speeds (60-90-120-150 rpm) were examined using the Taguchi experimental design method. In addition, an artificial neural networks (ANNs) model is utilized for modeling the wear at the cylinder liner (CL) and the piston rings (PR) using different fuel types, speeds and loads. As a result of the study, biodiesel fuel has a lower friction coefficient and abrasion in all load and cycle intervals due to its high viscosity and lubrication properties compared to diesel fuel. Besides, the developed ANN model has good predictive capability for the wear at the $\mathrm{CL}$ and the PR according to perfect match between experimental and modeling results.
\end{abstract}

Key Words: Engine, wear, friction, Taguchi method, biodiesel, Artificial neural networks (ANNs)

\section{Introduction}

For many years, researchers have been working to improve the efficiency of internal combustion engines [1]. The majority of the energy losses in internal combustion engines are the mechanical losses that occur between the relative moving parts [2]. Mechanical efficiency in engines is directly related to friction losses. An important part of the induced power is used to overcome the friction. Therefore, mechanical efficiency is important in terms of friction engine efficiency and fuel economy. In diesel 
engines, mechanical friction losses are even higher due to substantial mechanical loses in mechanical fuel pumps. Mechanical losses account for approximately 17\% of the lost energy. Mechanisms causing mechanical losses in engines include piston-crank mechanism, piston ring-cylinder liner, fuel pump in diesel engines and other auxiliary mechanisms. The loss of energy between the ring and cylinder liner comprise $20-40 \%$ of total mechanical losses and is considered as the largest mechanical loss [2-11].

In internal combustion engines, due to the dynamic working conditions, changes can be seen in the lubrication regime depending on the position of the piston in the cylinder. Since the piston speed is zero at the dead center where the piston changes direction, the friction coefficient increases and a transition occurs from hydrodynamic lubrication to mixed lubrication or boundary lubrication regime. The minimum oil thickness forms during combustion in the top dead center (TDC). With the increase in gas pressure on the ring, oil film thickness decreases. During the expansion stroke, oil film thickness increases with the increasing piston speed and the hydrodynamic lubrication regime occurs. Under higher load conditions, the loads on the ring increase due to the increase in gas pressure. Thinning can occur in oil film due to increased load. In addition, the increase in pressure increases the oil temperature and decreases the viscosity of the oil. In vehicle engines, cold starting period, sudden changes in load and speed are the other factors that cause the lubrication regime in engines [2,12-13].

There are numerous researches on the mechanical losses in internal combustion engines. In majority of these studies, the pin-on disc experiment setups were adopted. With these systems, the changes in friction and wear characteristics between the rotating engine parts can be determined accurately. However, the work in engines is obtained by the linear movement of the piston in the cylinder. Therefore, to determine the wear and friction characteristics between the ring-cylinder pairs, it is necessary to use test setups that will reflect the actual working conditions [1-11].

When researches are examined, biodiesel is used as an alternative fuel in diesel engines. In these studies, biodiesel is mixed with diesel fuel in certain proportions. [14-21]. Handan et al. [22], examined the effects of biodiesel (Palm Methyl Ester) addition to SAE10W40 and SAE5W40 engine oils at different volumetric ratios ranging from $10 \%$ to $90 \%$ on friction and wear in a wear device. The researchers found that the friction coefficient and wear values increased as the biodiesel ratio in the oil 
increased. In addition, the researchers experimentally determined that the lubrication regime shifts from the hydrodynamic lubrication regime to the mixed lubrication regime as the load increases, resulting in wear in the material. Chaudhari and Sutaria [23], experimentally studied the friction and wear effects of SAE40 and SAE10W30 lubricants at different speeds and viscosities in a linear-moving wear device. The experimental study was conducted at $60 \mathrm{~N}$ load and at different speeds between $300 \mathrm{rpm}$ and 1500 $\mathrm{rpm}$. As a result of the experimental study, it was determined that the friction coefficient decreased as the speed increased. The lowest friction coefficient was obtained from SAE10W30 lubricant at 1500 rpm [23]. Hisham et al.[24] experimentally examined the effects of four different lubricants on friction and wear under different conditions. The researchers used SAE40, waste cooking oil, 5\% waste cooking oil $+95 \%$ SAE40 or $10 \%$ waste cooking oil $+90 \%$ SAE40 as lubricant. The experiments were performed at 200,250 or $300 \mathrm{rpm}$ intervals and under 20,55 or $90 \mathrm{~N}$ loads. As a result, it has been reported that speed, load and lubricant have an effect on the friction coefficient and wear. The best result was obtained in the SAE40 lubricant. The friction coefficient and wear values increased as the ratio of waste meal oil added to the SAE40 lubricant increased. Sung et al. [25], experimentally investigated the changes in friction coefficient as a result of the transitions in the lubrication regimes during the linear movement of the ring on the cylinder. In the study, it was determined that the maximum friction coefficient formed at the dead center positions where boundary lubrication was observed while the minimum friction coefficient was determined during the middle stroke where the piston speed reached the highest value. The researchers, in their study using the $5 \mathrm{~W} 30$ lubricant oil, found that the friction coefficient was 0.14 at the dead centers and 0.03 during the middle stroke.

Wu et al. [26], used the Taguchi method to investigate the combustion characteristics of a diesel engine using diesel/ biodiesel mixtures with LPG (Liquid Petroleum Gas) where a cold EGR (Exhaust Gas Recirculation) was applied to the intake manifold and to determine the optimum factors. The researchers used Taguchi method to determine the optimum fuel consumption in their experimental study. The experiments were carried out at $1500 \mathrm{rpm}$ with different loads. The results showed that the predictions made with the Taguchi method were quite compatible with the practical results, indicating that this method has been instrumental to reduce the number of experimental studies in this study. The 
best fuel consumption time, waste gas and NOx (Nitrogen Oxides) values in each load were obtained with B10 (A1), 40\% LPG (B3) and 20\% EGR combination. Ganapathy et al. [27]-utilized Taguchi's optimization approach to identify the optimum engine design and operating parameters for the thermodynamic model analysis of an engine operating with Jatropha biodiesel. A thermodynamic model based on double-Wiebe function for heat release was used to determine the performance of the engine operating with Jatropha biodiesel. Ten critical parameters which are considered to interact with each other among the parameter pairs of important engine design and operation parameters were selected. An L16 orthogonal sequence was used to determine the test order of the engine using the linear graph theory and the Taguchi method. To maximize the performance of the engine, signal-noise ratio (SNR) was used based on "the higher the better" quality characteristics. As a result of the study, it was determined that the compression ratio is the most important parameter. After compression ratio, the best parameters are respectively diffusive zone heat release constant, diffusive zone combustion duration. [27]. Tan et al. [28] conducted an optimization study on biodiesel production process with trans esterification method using the Taguchi method. The effective parameters in biodiesel production process are molar ratio, catalyst concentration, reaction temperature and reaction time. According to researchers the Taguchi method, found that the most effective parameter on biodiesel production was the reaction temperature. Increasing the friction coefficient in internal combustion engines also increases the loss of material from the part surface. This factor reduces engine efficiency. Liquid fuels used in engines have lubricating properties. Liquid fuels contribute to the reduction of friction and wear losses due to the plastering of the cylindrical walls. Also, it is clear that the improvement in the lubricating properties of the fuel used will result in reductions in the mechanical friction losses caused by the fuel pump in diesel engines [12].

We attempt to explore was also an attempt to explore the possibility of using ANNs (artificial neural network) technology to predict the wear at the cylinder liner and the piston rings with different fuel types, speeds and loads. In the literature, Babu et al. [29], applied an ANNs model to predict engine characteristics (engine torque, effective power, effective efficiency, specific fuel consumption and cylinder pressure) for a common rail direct injection assisted diesel engine characteristics used with 
biodiesel and conventional diesel. This study reported that developed ANNs model have robust prediction capability for engine characteristics with the acceptable statistical error measurement values between predicted and experimental results. Huang et al. [30], applied three experimental models (Taguchi method, Taguchi and response surface methodology, and Taguchi, neural network, and genetic algorithm) for the quality improvement of piston manufacturing process processes. As a result of the study, Taguchi model performed best experimental efficiency compared to the other two models. In the study, it has been observed that all the statistical models used reduce the number of experiments in determining the piston production methods in order to reduce the error rate and increase efficiency. Tosun et al. [31], carried out a modeling work using linear regression and artificial neural networks to predict engine performance and exhaust emissions for a naturally aspirated diesel engine. This study reported that more accurate results were obtained using ANN to predict desired (torque, carbon monoxide and oxides of nitrogen) parameters according to linear regression model.

The studies cited above considered the application of some experimental models for the quality improvement of manufacturing process, estimating the engine performance, exhaust emissions, torques, fuel consumption etc., and reducing the number of experiments in the development phase for diesel engines. However, the ability of the combined usage of Taguchi and ANN to predict and optimize of the wear at the cylinder liner and the piston rings with different fuel types, speeds and loads for a diesel engine have not been adequately investigated in the literature. Thus, this study was carried out to fill this gap in the literature.

\section{Materials and Method}

\subsection{Experimental study}

In engines, since the boundary friction condition is dominant especially during start and at the TDC (top dead center), low speed ranges $(60,90,120$ and $150 \mathrm{rpm})$ were particularly selected during the experiments. In an engine running at $1000 \mathrm{rpm}$, the piston speed rapidly increases after $20^{\circ} \mathrm{CA}$ (crank angle). This increase in speed causes the lubrication regime to shift from the boundary friction to hydrodynamic friction. However, the momentary piston speed values at the selected speeds were considerably lower than the momentary piston speed value at $1000 \mathrm{rpm}$. Thus, these selected speed 
ranges are important both for frictions during the start and for more realistic analysis of friction at low piston speeds up to the first $20^{\circ} \mathrm{CA}$ at normal operating speeds.

The friction and wear tests were carried out in a linear moving wear device. Wear tests were performed in accordance with the ASTMG133-05 standards. A schematic view of the wear test device is given in Figure 1.

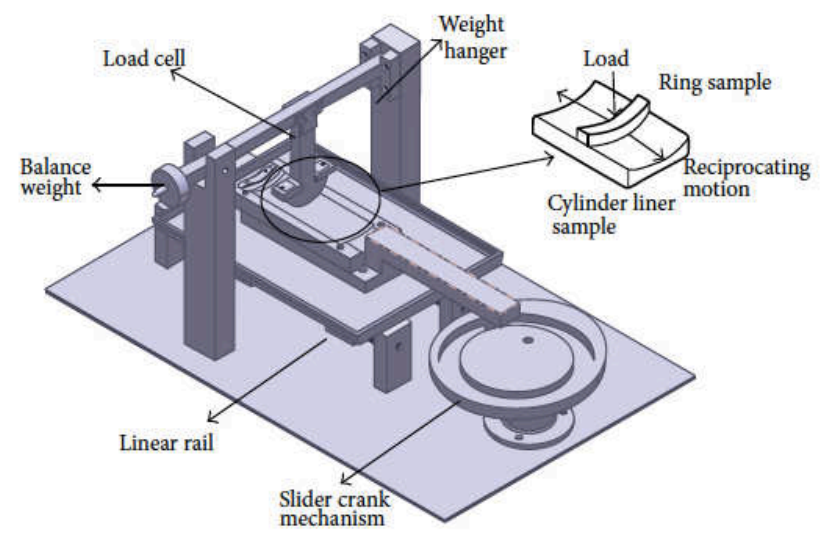

Figure 1. Piston ring reciprocating liner test machine, contact geometry, and test sample.

The wear device operates in a linear motion just as the ring-cylinder pair does in actual conditions. The wear test device was operating according to the working principle of the engines; the liner sample was fixed whereas the ring sample was mobile. In the wear test device, normal loads were applied by hanging weights to the carrier arm to which the ring sample was connected to give the desired value to the carrier arm. The experiments were conducted at $60,90,120$ or $150 \mathrm{rpm}$ speeds and under 40 , 60,80 or $100 \mathrm{~N}$ loads. Test conditions are given in Table 1 . The experiments were carried out at the regimen temperature of an internal combustion engine $\left(75 \pm 5^{\circ} \mathrm{C}\right)$.

Table 1. Tribotest conditions

\begin{tabular}{lc}
\hline Test specifications & Values \\
\hline Load, $\mathrm{N}$ & $40-60-80-100$ \\
Engine Speed, rpm & $60-90-120-150$ \\
Temperature, ${ }^{\circ} \mathrm{C}$ & 75 \\
Stroke, $\mathrm{m}$ & 0.1 \\
Oil supply, $\mathrm{ml} / \mathrm{h}$ & 0.5 \\
Distance, $\mathrm{m}$ & 5000 \\
Lubricant & DIESEL-COME \\
\hline
\end{tabular}


Ring samples were used by cutting the chrome coated rings which are used in the industry in ring shape. The cylinder sample was obtained from the iron-cast liner. The properties of ring and liner samples used in the experiments are given in Table 2.

Table 2. Piston ring and cylinder liner specifications

\begin{tabular}{lllcc}
\hline Sample & Material & Surface treatment & Hardness $\left(\mathrm{HV}_{0.1}\right)$ & Roughness $\left(\mathrm{R}_{\mathrm{a}}, \mu \mathrm{m}\right)$ \\
\hline Ring & Cast iron & Chrome coated & 920 & 0.121 \\
Liner & Cast iron & Honing & 20.3 & 1.052 \\
\hline
\end{tabular}

In the wear tests, covering a $5000 \mathrm{~m}$ distance was taken into account. The experiments were carried out separately for each speed under different loads for the time period to cover $5000 \mathrm{~m}$ distance. In the experiments, the width of the ring sample on the liner was adjusted to $0.010 \mathrm{~m}$ for each test.

The amount of wear is measured by three methods. These are: weight difference method, thickness difference method and trace change method. In this study, the weight difference method has been used to obtain accurate results on the amount of wear. A precision scale with $10^{-4} \mathrm{~g}(0.1 \mathrm{mg})$ sensitivity was used to determine the wear value. Liner and ring samples were cleaned with ethanol before each experiment and then the samples were measured in the precision balance. After each experiment, the samples were again washed with ethanol, dried and then measured in a precision scale. The wear values were determined by determining the differences between the measured values.

In the experiments, $100 \%$ Diesel and 100\% COME (chicken oil methyl ester) were used as lubricants. Lubricants were given to the experiment set dropwise, at a flow rate of $0.5 \mathrm{ml}$ per hour. The properties of the lubricants used in the experiments are given in Table 3.

Table 3. Properties of the lubricant used in experiment [25-27]

\begin{tabular}{llll}
\hline Properties & Standards & Euro Diesel & COME \\
\hline $\begin{array}{l}\text { Kinematic Viscosity } 40^{\circ} \mathrm{C} \mathrm{mm}^{2} / \mathrm{s} \\
100^{\circ} \mathrm{C} \mathrm{mm} / \mathrm{s}\end{array}$ & ASTM D 445 & 3.25 & 3,5 \\
& & & \\
Viscosity Index & ISO 2909 & $2-4,5$ & $3,5-5$ \\
Density $15^{\circ} \mathrm{C} \mathrm{kg} / \mathrm{dm}^{3}$ & ASTM D 4052 & 0.84 & 0,860 \\
& & & \\
Pour point, ${ }^{\circ} \mathrm{C}$ & ISO 3016 & -10 & -15 \\
Flash Point,${ }^{\circ} \mathrm{C}$ & ASTM D 92 & 55 & 120 \\
\hline
\end{tabular}




\subsection{Experimental Design}

The experimental study was carried out by Taguchi experimental design method. The most important distinguishing feature of the Taguchi method is the determination of the results according to the signal pattern ratio $(\mathrm{S} / \mathrm{N})$ of the experiments performed without too much experimentation. In the study, the optimum levels of factors were determined for two different lubricants at four different speeds under four different loads. In the experimental design, speed, load and fuel type, which are effective on friction and wear, were chosen as the effective factors (Table 4).

Table 4. Factors design and factor levels

\begin{tabular}{|l|l|l|l|l|l|}
\hline Symbol & Factors & Level 1 & Level 2 & Level 3 & Level 3 \\
\hline A & Fuel & Diesel & COMO & - & - \\
\hline B & Speed, rpm & 60 & 90 & 120 & 150 \\
\hline C & Load, N & 40 & 60 & 80 & 100 \\
\hline
\end{tabular}

All test steps were repeated 10 times and the experimental data were obtained by taking the average. The friction coefficient was determined by taking the average of the friction coefficient obtained at 360 degrees. In the wear tests, measurements were made 10 times and the average amount of wear was determined.

The basic principle of the Taguchi method is to determine the effect of various individual and combined design effects on the parameters observed with the minimum number of experiments. Taguchi method uses a generic Signal-to-Noise $(\mathrm{S} / \mathrm{N})$ ratio to quantify the present variation. There are several $\mathrm{S} / \mathrm{N}$ ratios available depending on the type of characteristics including 'Lower is Better' (LB), 'Nominal is Best' (NB), and 'Higher is Better' (HB). The S/N ratio for the LB characteristics is related to the present study, which is given by

$$
\begin{aligned}
& \mathrm{S} / \mathrm{N}=-10 \log \left(\frac{1}{n} \sum_{i=1}^{n} y_{i}^{2}\right) \\
& \mathrm{S} / \mathrm{N}=-10 \log \left(\frac{1}{n} \sum_{i=1}^{n} \frac{1}{y_{i}^{2}}\right)
\end{aligned}
$$

where $\mathrm{n}$ is the number of repetition in a trial under the same design conditions, yi represents the measured value, and subscript $\mathrm{i}$ indicates the number of design parameters in the orthogonal array (OA). In the Taguchi method, a design parameter (factor) is considered to be significant if its influence is large 
compared to the experimental error as estimated by the analysis of variance (ANOVA) statistical method given by Eqs. (3)-(7) shown below. If this is the case, the design parameter is a critical factor in determining the optimal solution to the design problem:

$\mathrm{SS}_{\mathrm{T}}=\left[\sum_{i=1}^{N}(S / N) i^{2}\right]-\frac{T^{2}}{N}$

$\mathrm{SS}_{\mathrm{A}}=\left[\sum_{i=1}^{K_{A}}\left(\frac{A_{i}^{2}}{n_{A i}}\right)\right]-\frac{T^{2}}{N}$

$v_{\text {total }}=\mathrm{N}-1$

$\mathrm{V}_{\text {factor }}=\frac{S S_{\text {factor }}}{v_{\text {factor }}}$

$\mathrm{F}_{\text {factor }}=\frac{\mathrm{V}_{\text {factor }}}{V_{\text {error }}}$

where, SST is the sum of squares due to total variation, $\mathrm{N}$ is the total number of experiments, SSA represents the sum of squares due to factor A, KA is number of levels for factor A. Ai stands for the sum of the total ith level of the factor A, nAi is the number of samples for ith level of factor $\mathrm{A} . \mathrm{T}$ is the sum of total $(\mathrm{S} / \mathrm{N})$ ratio of the experiments, vtotal is the degrees of freedom, Vfactor is the variance of the factor, SSfactor represents the sum of squares of the factor and Ffactor is the F ratio of the factor. In Taguchi methods, the levels of factors given in the ANOVA are meaningful according to $90 \%$ and $99 \%$ confidence intervals. Design of experiments is composed considering these confidence limits. Required the minimum experimental layout according to Taguchi methods are given in Table 5. 
Table 5. Experimental (OA) Layout

\begin{tabular}{|c|c|c|c|}
\hline \multirow[t]{2}{*}{ Experimental No } & \multicolumn{3}{|c|}{ FACTORS } \\
\hline & $\mathbf{A}$ & B & C \\
\hline 1 & 1 & 1 & 1 \\
\hline 2 & 1 & 1 & 2 \\
\hline 3 & 2 & 1 & 3 \\
\hline 4 & 2 & 1 & 4 \\
\hline 5 & 1 & 2 & 3 \\
\hline 6 & 1 & 2 & 4 \\
\hline 7 & 2 & 2 & 1 \\
\hline 8 & 2 & 2 & 2 \\
\hline 9 & 1 & 3 & 3 \\
\hline 10 & 1 & 3 & 4 \\
\hline 11 & 2 & 3 & 1 \\
\hline 12 & 2 & 3 & 2 \\
\hline 13 & 1 & 4 & 1 \\
\hline 14 & 1 & 4 & 2 \\
\hline 15 & 2 & 4 & 3 \\
\hline 16 & 2 & 4 & 4 \\
\hline
\end{tabular}

\subsection{Artificial Neural Network Model}

The nervous system of the human body has inspired the creation of artificial neural networks (ANNs), and these systems are important artificial intelligence systems capable of solving a number of complex problems [32]. ANNs are the most remarkable modeling method among artificial intelligencebased methods. When compared with traditional mathematical methods, artificial neural networks have advantages such as the lack of necessity to make mathematical definitions of events in the process, having the ability to predict using a limited number of experiments [33].

ANNs consist of three layers, the input layer, the hidden layer and the output layer. In the ANNs, while the input layer consists of independent variables, the output layer consists of dependent variables. Between these two layers are hidden layers containing one or more neurons in layers ANNs have connections between process elements (neurons) to solve complex problems [34]. A schematic structure of the ANNs are showed in Figure 2. 


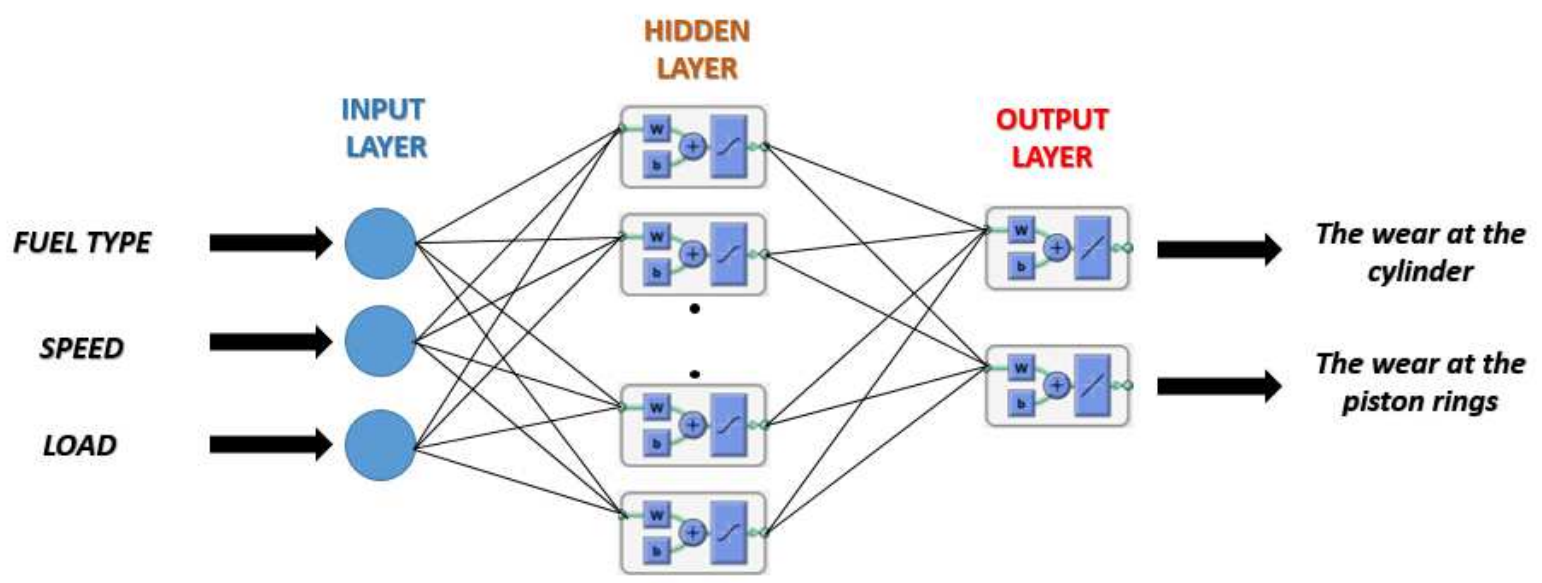

Figure 2. A Schematic structure of the artificial neural networks (ANNs)

\section{Results and Discussion}

In this study, Taguchi method was used to determine the optimum conditions for friction and wear in ring-cylinder pairs. Friction and wear tests were carried out according to the orthogonal experiment design given in Table 5 and the verification tests were carried out. The optimum design parameter levels were determined for friction and wear as a result of the experiments carried out according to $95-99.99 \%$ confidence interval. Figure 3.a shows the wear values between the cylinder liner and ring sample at different speeds under different loads in the case of using diesel fuel as lubricant. Figure 3.b shows the wear values in the cylinder-ring pairs in the case of using biodiesel fuel as lubricant. The reason for the decrease of friction coefficient and wear amount is thought to be better in density and lubrication properties than biodiesel fuel diesel fuel. 

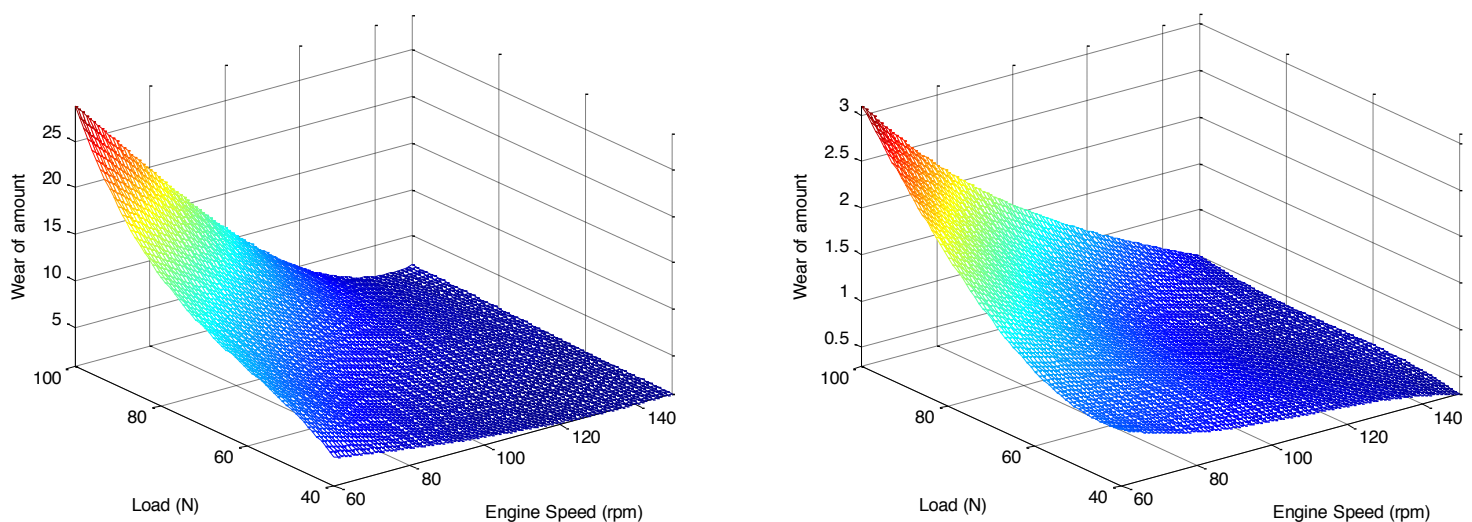

a)
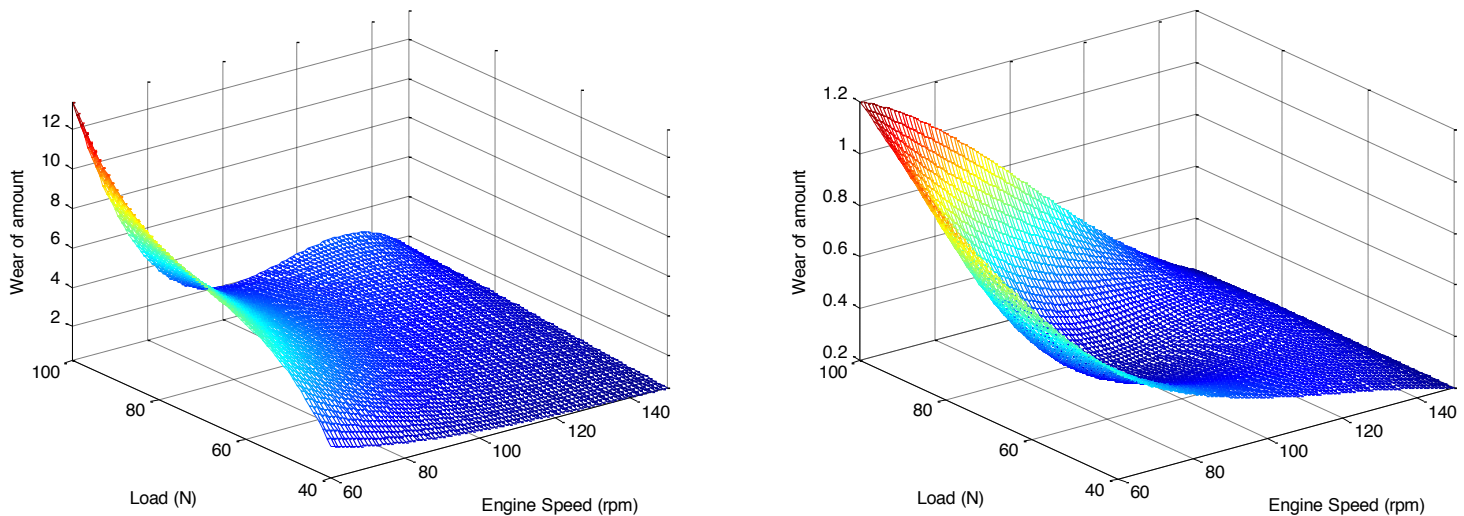

b)

Figure 3. Amount for wear at the cylinder and piston rings a) diesel fuels b) biodisel fuels

As seen in the signal to noise ratios in Figure 4.a, the minimum wear value in the cylinder liner was determined with biodiesel fuel, at $150 \mathrm{rpm}$ engine speed under $40 \mathrm{~N}$ load (A2B4C1). In the ring sample, similar to the wear in the liner, the optimum conditions were determined with biodiesel fuel at $150 \mathrm{rpm}$ engine speed under $40 \mathrm{~N}$ load (A2B4C1). In Figure 4.b, it is seen that the effects of the changes in load applied on the engine speed and the piston ring on the wear values varied. Decreases in the wear value can be regarded as a result of the decrease in tangential force on the ring due to the increase in piston speed with increase in the engine speed. However, with the increase in load, due to the increase in normal force on the piston ring, wear values increase. 


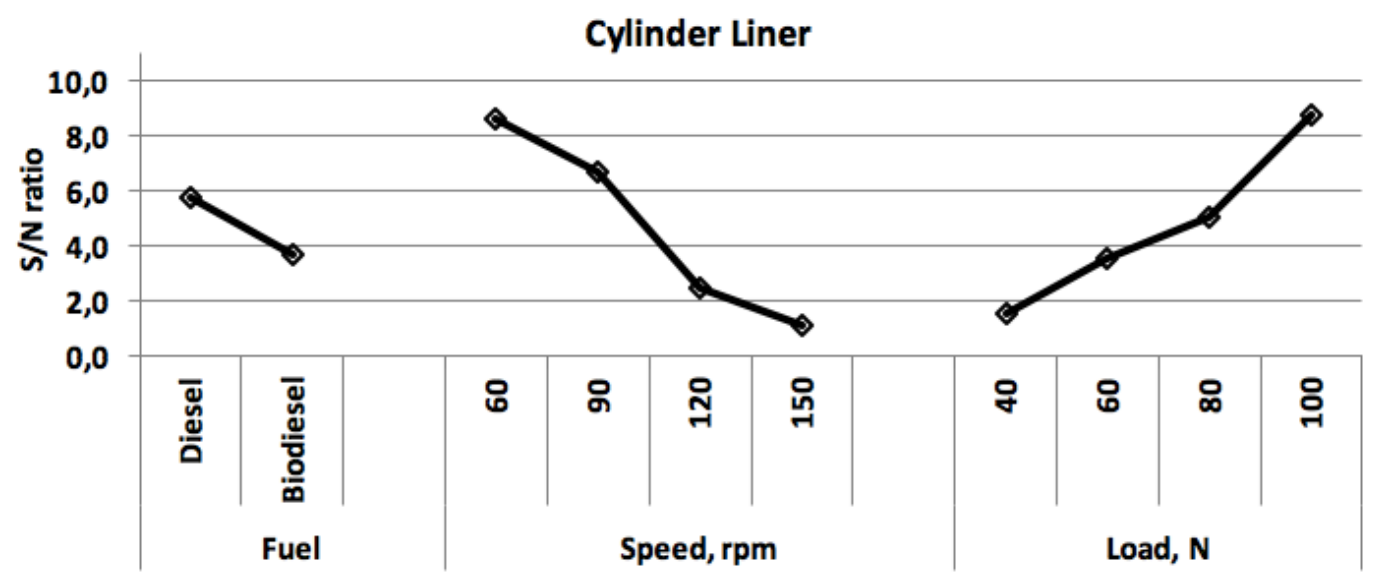

a)

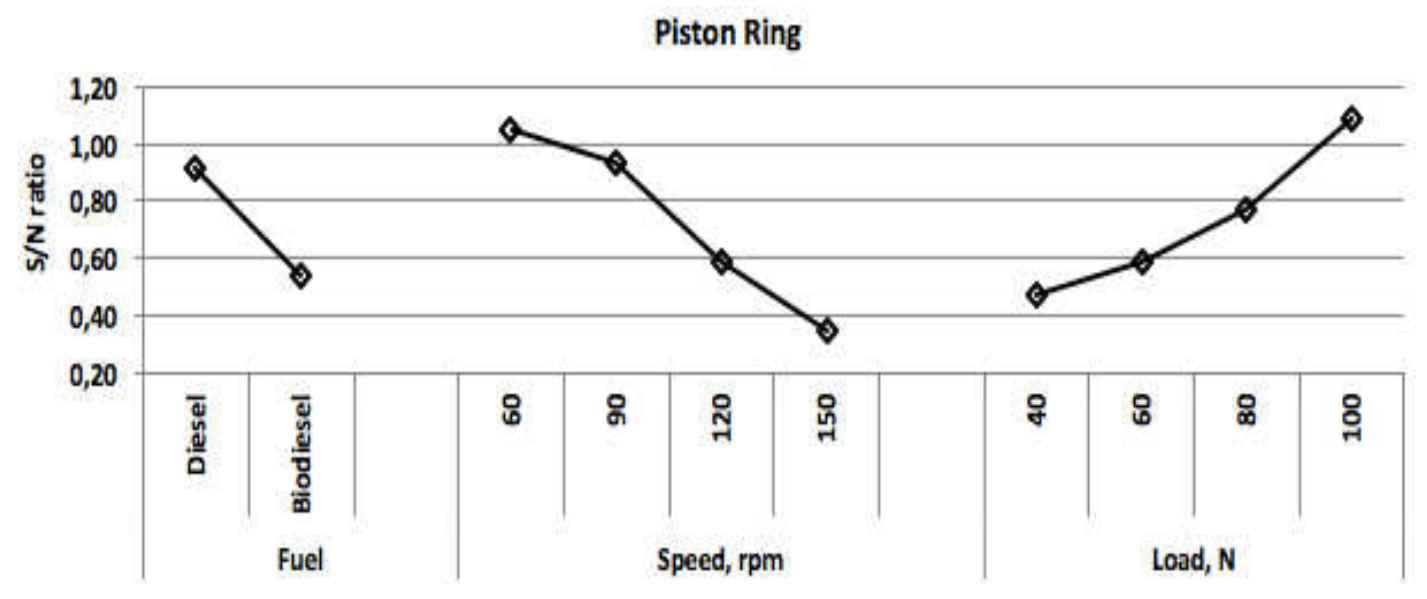

b)

Figure 4. $\mathrm{S} / \mathrm{N}$ values of factor levels at he wear, a) cylinder b) piston rings

Figure 5 shows the changes in friction coefficient in cylinder-ring pairs where diesel or biodiesel fuels are used as lubricants. 

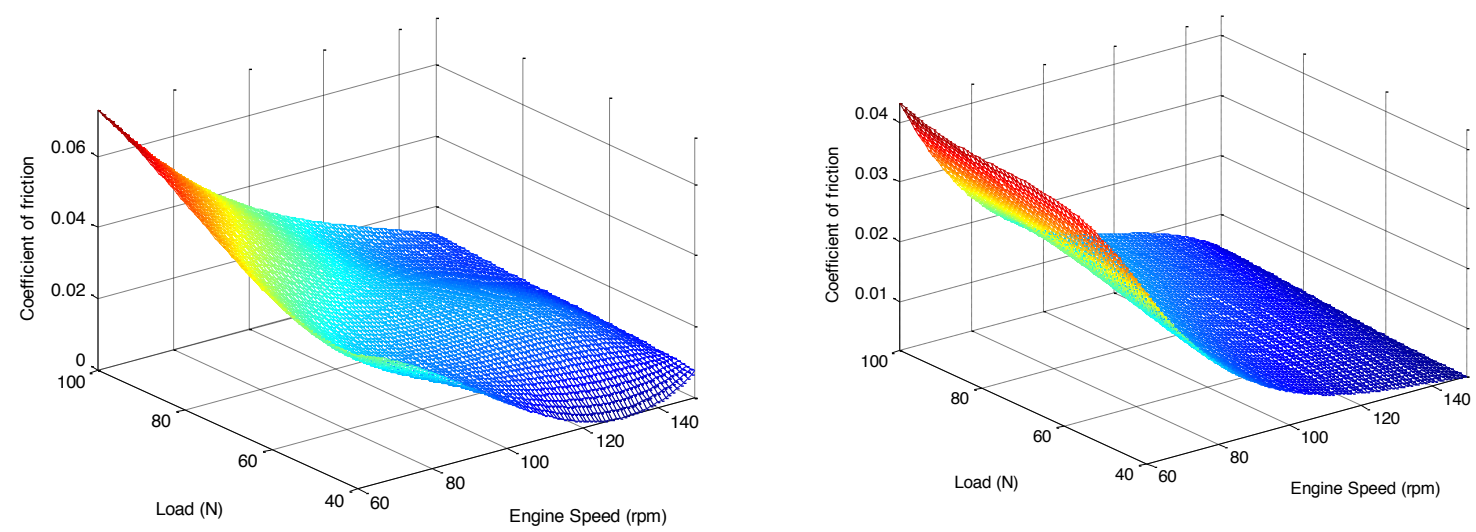

Figure 5. Variation of coefficient friction as diesel and biodiesel fuel at the among cylinder and piston rings

Figure 6 shows the changes in the friction coefficient in ring-cylinder pairs. Optimum conditions in terms of friction coefficient between cylinder-ring pairs were determined using biodiesel fuel at 150 rpm engine speed under $40 \mathrm{~N}$ load (A1B4C1).

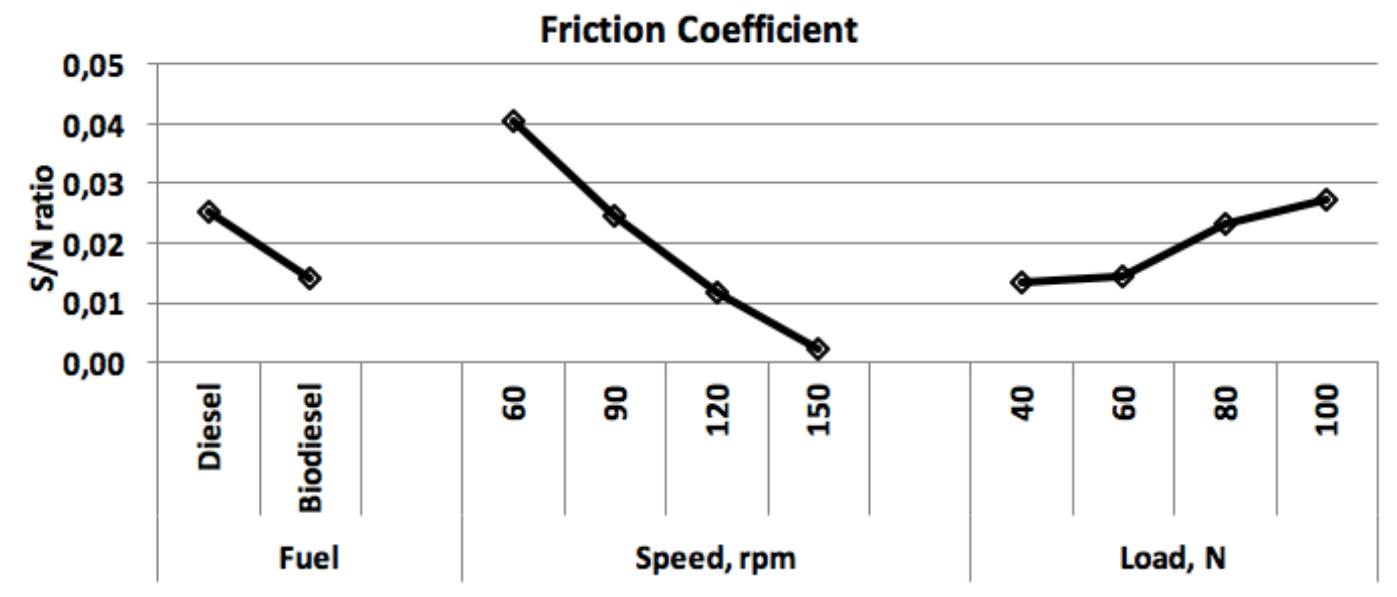

Figure 6. $\mathrm{S} / \mathrm{N}$ values of factor levels for friction coefficient

In the study, a total of 5 ANNs model was derived from a combination of 4 different topologies (LinR: linear regression-; MLPR: Regression multilayer perceptron; PNN: probabilistic neural network; GFFR: Regression generalized feed forward;), up to two hidden layers (0: no hidden layer; 1 vs. 2: the number of hidden layer), a learning algorithm (L: Levenberg-Marquardt) and learning mode (B: batch), and (N: None). In ANN modeling, experimental dataset was randomly partitioned into training, cross validation and testing datasets with the allocation order of $65 \%, 15 \%$ and $20 \%$, respectively. Datasets 
were fed into a total of 5 ANNs to predict the wear at the cylinder liner and the piston rings which included as inputs fuel types, speeds and loads. Performance statistics used for comparing ANNs were (MSE), mean absolute error (MAE) and coefficient of determination $\left(\mathrm{R}^{2}\right)$ as follow [35].

$\operatorname{MSE}=\frac{1}{\mathrm{~N}} \sum_{\mathrm{i}=1}^{\mathrm{N}}(\mathrm{yi}-\hat{y})^{2}$

$\mathrm{MAE}=\frac{1}{\mathrm{~N}} \sum_{\mathrm{i}=1}^{\mathrm{N}}|\mathrm{yi}-\hat{\mathrm{y}}|$

$\mathrm{R}^{2}=1-\frac{\sum\left(\mathrm{y}_{\mathrm{i}-\hat{\mathrm{y}}}\right)^{2}}{\sum\left(\mathrm{y}_{\mathrm{i}-\mathrm{y}}\right)^{2}}$

Where,

$\hat{Y}$ : Predicted value of $y$

$\overline{\mathrm{y}}$ : Mean value of y

Figure 7. The comparison of experimental and the best performing neural networks (MLPR-1B-L, Regression Multilayer Perceptron) for training, cross validation and testing for data number 1-21, 22-26, 27-32 respectively.

The predictive performance of the ANNs in terms of $\mathrm{R}^{2}$ values based on testing ranged from 0,823 by LinR-0-B-L (Linear Regression) to 0,998 by that MLPR-1-B-L (Regression Multilayer Perceptron). The performance statistics derived from training, cross validation and testing of the 5 ANNs indicated that MLPR-1-B-L performed best among the other ANNs as a function of fuel types, speeds and loads (Table 6). Testing-derived values of $\mathrm{R}^{2}$, MSE and MAE pointed to MLPR topologies (MLPR1-B-L) as the best ANNs. The comparison of experimental and best performing neural networks (MLPR-1-B-L) for training, cross validation and testing is demonstrated in Figure 8. As can be seen from Figure 7, the developed ANN model (MLPR-1-B-L) have good predictive capability for the wear at the cylinder liner and the piston rings in terms of $\mathrm{R}^{2}$, MSE and MAE values between experimental and modeling results. 

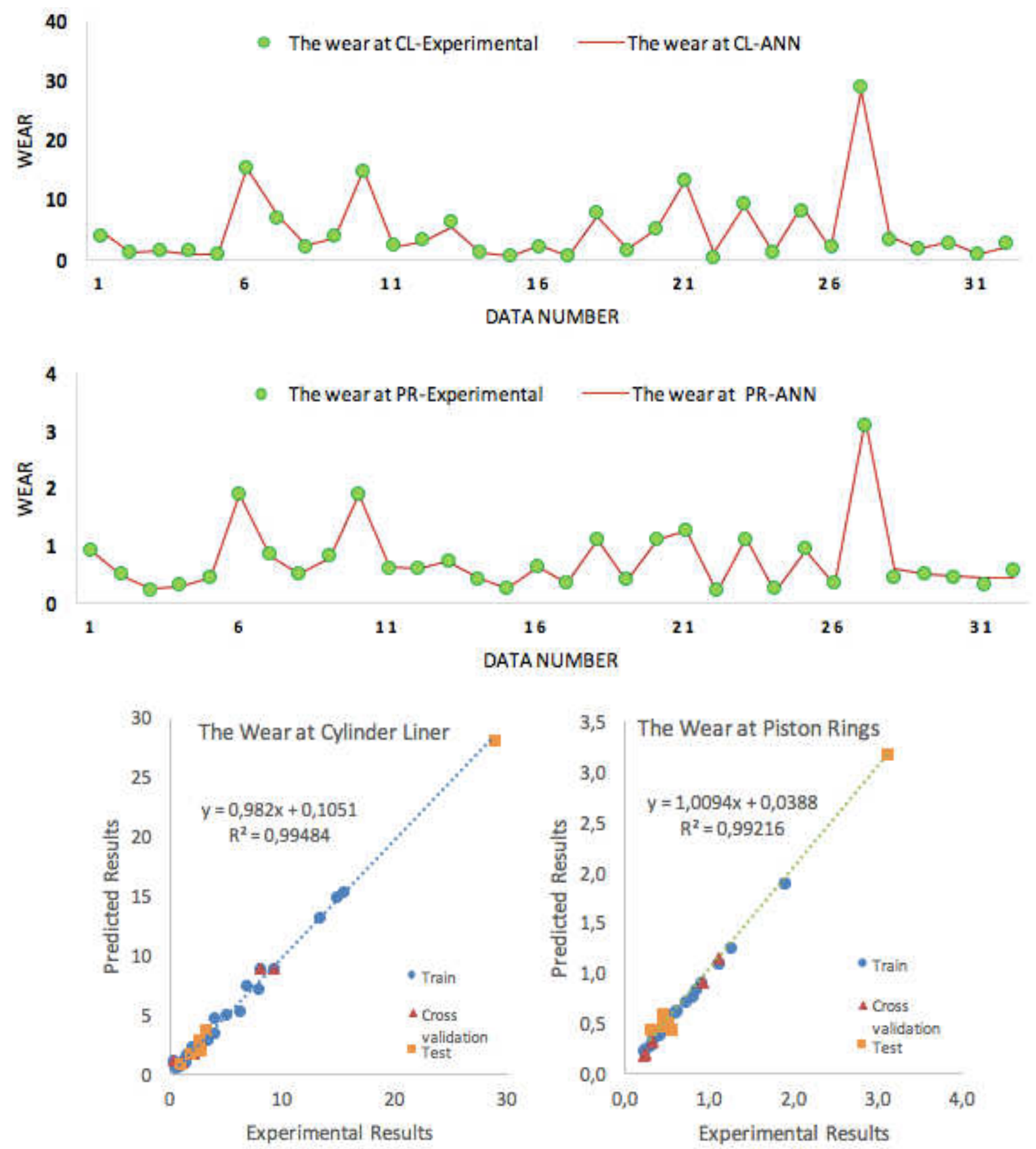

Figure 7. Experimental results versus $A N N$ in terms of the wear at cylinder liner (CL) and piston rings (PR) 
Table 6. A comparison of 5 artificial neural networks (ANNs) developed as a function of fuel types, speeds and loads by the wear at the cylinder liner and the piston rings based on performance metrics of training, crossvalidation and independent validation.

\begin{tabular}{|c|c|c|c|c|c|c|c|c|c|}
\hline \multirow[b]{2}{*}{ Artificial Neural Networks Models } & \multicolumn{3}{|c|}{ Training $(n=21)$} & \multicolumn{3}{|c|}{ Cross Validation $(n=5)$} & \multicolumn{3}{|c|}{ Testing $(n=6)$} \\
\hline & MSE & $\mathbf{R}^{2}$ & MAE & MSE & $\mathbf{R}^{2}$ & MAE & MSE & $\mathbf{R}^{2}$ & MAE \\
\hline LinR-0-B-L (Linear Regression) & 4,468 & 0,886 & 1,773 & 5,889 & 0,922 & 1,795 & 45,763 & 0,823 & 4,607 \\
\hline $\begin{array}{l}M L P R-1-B-L(\text { Regression Multilayer } \\
\text { Perceptron) * }\end{array}$ & 0,149 & 0,996 & 0,302 & 0,282 & 0,991 & 0,422 & 1,354 & 0,998 & 0,742 \\
\hline $\begin{array}{l}\text { PNN-0-N-N (Probabilistic Neural } \\
\text { Network) }\end{array}$ & 0,001 & 0,999 & 0,015 & 1,200 & 0,958 & 0,852 & 34,29 & 0,946 & 3,316 \\
\hline $\begin{array}{l}\text { GFFR-1-B-L (Regression Generalized } \\
\text { Feedforward) }\end{array}$ & 0,213 & 0,998 & 0,141 & 3,553 & 0,914 & 1,602 & 7,705 & 0,992 & 1,675 \\
\hline $\begin{array}{l}\text { MLPR-2-B-L (Regression Multilayer } \\
\text { Perceptron) }\end{array}$ & 0,024 & 0,999 & 0,128 & 2,129 & 0,931 & 1,034 & 6,733 & 0,991 & 1,614 \\
\hline $\begin{array}{l}\text { *The best performing ANN is designate } \\
\text { Explanations of ANN Model Topologie } \\
\text { probabilistic neural network; GFFR: Re } \\
\text { vs. 2: the number of hidden layer), lea } \\
\text { (N:None) }\end{array}$ & italic. & thm & Lev & erg-M & uardt & nd le & ing & e (B & $\begin{array}{l}\text { n; PNN: } \\
\text { layer; } 1 \\
\text { ch), and }\end{array}$ \\
\hline
\end{tabular}

\section{Conclusion}

In the study, the effects of different lubricants on the friction and wear in the piston ring and cylinder under different speed and load conditions were experimentally investigated using the Taguchi test design method. In internal combustion engines, maximum wear occurs at the first movement and TDC at low piston speeds. In the study, the round per minute values where the maximum wear value was obtained were taken into consideration. As a result of the study, the optimum conditions which determine the minimum friction coefficient and wear values were determined. In addition, an artificial neural networks (ANNs) model is utilized for modeling the wear at the cylinder liner and the piston rings using different fuel types, speeds and loads.

Results obtained from the study are as follows;

1.Utilizing the Taguchi experimental design method, the minimum values of friction and wear were determined in the cylinder-piston pair.

2.Biodiesel use was found to yield lower results in terms of friction and wear compared to diesel fuel. 3.In terms of friction and wear, the minimum values were obtained at $150 \mathrm{rpm}$ speed under $40 \mathrm{~N}$ load. 
4.With lower number of experiments, the Taguchi method has been found to be an effective tool to investigate the effects of several factors on friction coefficient and wear.

5. The experimental results are modeled by artificial neural networks (ANNs). According to ANN modelling, it is seen that R2 between experimental and predicted output variable for different neural network architecture varies in the range of 0.823-0.998.

6. The performance statistics (in Table 6) derived from training, cross validation and testing of the 5 different ANN models (architecture) indicated that MLPR-1-B-L (Regression Multilayer Perceptron) performed best among the other ANNs as a function of fuel types, speeds and loads.

7. Since the developed best ANN model (MLPR-1-B-L) has a good predictive ability, it can be used for estimation of the wear at the cylinder liner and the piston rings with different fuel types, speeds and loads. Thus, the number of experiments can be reduced and both time and cost can be saved. Thus, by reducing the number of experiments to be performed, both time and cost can be saved.

\section{References}

[1] i. Cesur, V. Ayhan, A. Parlak, Ö. Savaş, Z. Aydın. (2014). The Effects of Different Fuels on Wear between Piston Ring and Cylinder, Hindawi Publishing Corporation Advances in Mechanical Engineering, Article ID 503212, 8 pages, 2014/503212.

[2] J.B.Heywood. (1988). International Combustion Engine Fundamentals, McGraw Hill Book Company, New York.

[3] G. Ryk, I. ETSION. (2005). Testing piston rings with partial laser surface texturing for friction reduction" Department of Mechinical Engineering, Techion, Haifa 32000 Israel.

[4] C. S. Tung, G. Hong. (2003). Tribological characteristics and surface interaction between piston ring coatings and a blend of energy-conserving oils and ethanol fuels, Wear, Volume 255, Issues 7-12,

[5] H.X. Guizhen, H.L. Jonah, L. Hong, G. Doglas. (2003). Tribological properties of solid-lubricating coatings on cylinder bore at low temperature, DOI: 10.1016/j.wear.2003.08.005.

[6] C. Sung-Woo, C. Sang-Min, B.Choong-Sik. (2000). Frictional modes of barrel shaped piston rings under flooded lubrication, Tribology International, Volume 33, Issue 8.

[7] Truhan, J.J., Qu. J., Blau. P., J. (1996). A ring test to measure friction and wear of heavy duty diesel engine piston rings and cylinder liners using realistic lubricants", University of Tennessee, Knoxville, TN 37996, USA.

[8] M. Çakır, M. Akçay, İ.H. Akçay. (2011). An Investigation On The Relationship Between Segman-Shirt Friction With Motor Performance In Internal Combustion Engines, BÜ, Soma Vocational School, Technical Sciences Journal, C:2, Say1:16.

[9] B.S. Andersson. (1991). Company perspectives in vehicle tribology - Volvo, 17th Leeds- Lyon Symposium on Tribology - Vehicle Tribology, 18:503-506.

[10] P.C. Mishra, H. Rahnejat, P.D.King. (2009). Tribology of the ring-bore conjunction subject to a mixed regime of lubrication, Proc. IMechE Part C: J. Mechanical Engineering Science, 223:987-998.

[11] A. Spencer. (2010). Optimizing Surface Texture for Combustion Engine Cylinder Liners, Lulea University of Technology, Licentiate Thesis, p.104.

[12] M. Priest, C.M. Taylor. (2000). Automobile engine tribology-approaching the surface, School of Mechinical Engineering. The University of leeds, Woodhouse Lane, Leeds, LS2 JT, UK.

[13] C.M. Taylor, (1993,) Lubrication Regimes and Internal Combustion Engine, Elsevier Science Publishers, Leeds England. 
[14] Sapaun SM, Masjuki HH, Azlan A. (1996). The use of palm oil as diesel fuel substitute. J Power Energy - Part A;210:47-53.

[15] Murayama T, Oh Y-T, Miyamoto N, Chikahisa T, Takagi. (1984). N. Low carbon flower build up, low smoke and efficient diesel operation with vegetable oils by conversion to monoesters and blending with diesel oil or alcohols. SAE Paper 841161.

[16] Ali Y, Hanna Milford A, Borg Joseph E. (1995). Optimization of diesel Methyl tallowate and ethanol blend for reducing emissions from diesel engine. Bioresour Technol; 52:237-43.

[17] Manigandan S, Gunasekar P, Devipriya J, Nithya S, (2019), Emission and injection characteristics of corn biodiesel blends in diesel engine. Fuel;235:723-35.

[18] Usta N, Can Ö, ve Özgtürk E. (2005). Comparison of biodiesel and ethanol as alternative diesel engine fuel, Pamukkale University Faculty of Engineering. J Eng Sci 2005(3).

[19] Ozsezen AN, Canakci M. (2011). Determination of the performance and combustion characteristics of a diesel engine with canola and waste palm oil methyl esters. Energy Conserv Manage 2011;52:108-16.

[20] Devan PK, Mahalakshmi NV. (2009). Performance emission and combustion characteristics of poon oil and its diesel blends in a DI diesel engine. Fuel 2009;88:861-7.

[21] Karaosmanoğlu F, Kurt G, Özaktaş T. (2000). Long term CI engine test of sunflower oil. Renewable Energy 2000;19:219-21.

[22] S.H. Hamdana, W.W.F. Chongcidie, J.-H. Ngbif, C.T. Chongcid, S. Rajoocid. (2017). A study of the tribological impact of biodiesel dilution on engine lubricant properties", Process Safety and Environmental Protection, http://dx.doi.org/10.1016/j.psep.2017.05.007.

[23] T. Chaudhari, B. Sutaria. (2016). Investigation of friction characteristics insegmented piston ring liner assembly of ICengine, Perspectives in Science 8, 599-602.

[24] S. Hisham, K. Kadirgama, D. Ramasamy, M.M. Noor, A.K. Amirruddin , G. Najafi, M.M. Rahman. (2017). Waste cooking oil blended with the engine oil for reduction of friction and wear on piston skirt, Fuel 205 2017, 247-261

[25] S.W. Cho, S.M. Choi, C.S. Bae. (2000). Frictional models of barrel shaped piston rings under folded lubrication, Department of Mechanical Engineering, Korea Advanced Institute of Science and Technology, KAIST 373-1,1.

[26] Z.Y. Wu, H.W. Wu, C.H. Hung. (2014). Applying Taguchi method to combustion characteristics and optimal factors determination in diesel/biodiesel engines with port-injecting LPG, Fuel 117, 8-14.

[27] T. Ganapathy, K. Murugesan , R.P. Gakkhar. (2009). Performance optimization of Jatropha biodiesel engine model using Taguchi approach, Applied Energy 86, 2476-2486.

[28] Y.H. Tan, M.O. Abdullah, C.N. Hipolito, N.S.A. Zauzi. (2017) Application of RSM and Taguchi methods for optimizing the transesterification of waste cooking oil catalyzed by solid ostrich and chicken-eggshell derived $\mathrm{CaO}$, Renewable Energy 114, 437-447.

[29] Babu, D., Thangarasu, V., and Ramanathan, A. (2020). Artificial neural network approach on forecasting diesel engine characteristics fuelled with waste frying oil biodiesel, Applied Energy, 263, p. 114612.2020.

[30] Huang M-L, Hung Y-H, Yang Z-S. (2016)i Validation of a method using Taguchi, response surface, neural network, and genetic algorithm. Measurement, 94:284-294.

[31] Tosun, E., Aydin, K., and Bilgili, M. (2016). Comparison of linear regression and artificial neural network model of a diesel engine fueled with biodiesel-alcohol mixtures”, Alexandria Engineering Journal, 55(4), pp. 3081-3089.

[32] Yaqub, M., Eren, B., and Eyupoglu, V. (2019). Soft computing techniques in prediction Cr(VI) removal efficiency of polymer inclusion membranes", Environ. Eng. Res., 25(3), pp. 418-425.

[33] Hasani, G., Daraei, H., Shahmoradi, B., Gharibi, F., Maleki, A., Yetilmezsoy, K., and McKay, G. (2018) A novel ANN approach for modeling of alternating pulse current electrocoagulation-flotation (APC-ECF) process: Humic acid removal from aqueous media", Process Saf. Environ. Prot., 117, pp. 111-124.

[34] Aber, S., Amani-Ghadim, A. R., and Mirzajani, V. (2009). Removal of Cr(VI) from polluted solutions by electrocoagulation: Modeling of experimental results using artificial neural network", J. Hazard. Mater., 171(1-3), pp. 484-490.

[35] Dogan, E., Ates, A., Yilmaz, E. C., and Eren, B. (2008). Application of artificial neural networks to estimate wastewater treatment plant inlet biochemical oxygen demand, Environ. Prog., 27(4), pp. 439446. 


\section{Availability of data and materials}

All authors have participated in conception and design, or analysis and interpretation of the data. No data, models, or code were generated or used during the study.

\section{Competing interests}

The authors declare no competing financial interests.

\section{Funding}

Not applicable

\section{Author contribution}

All authors have contributed in the article. All authors read and approved the final manuscript.

\section{Acknowledgements}

Not applicable 


\section{Figures}

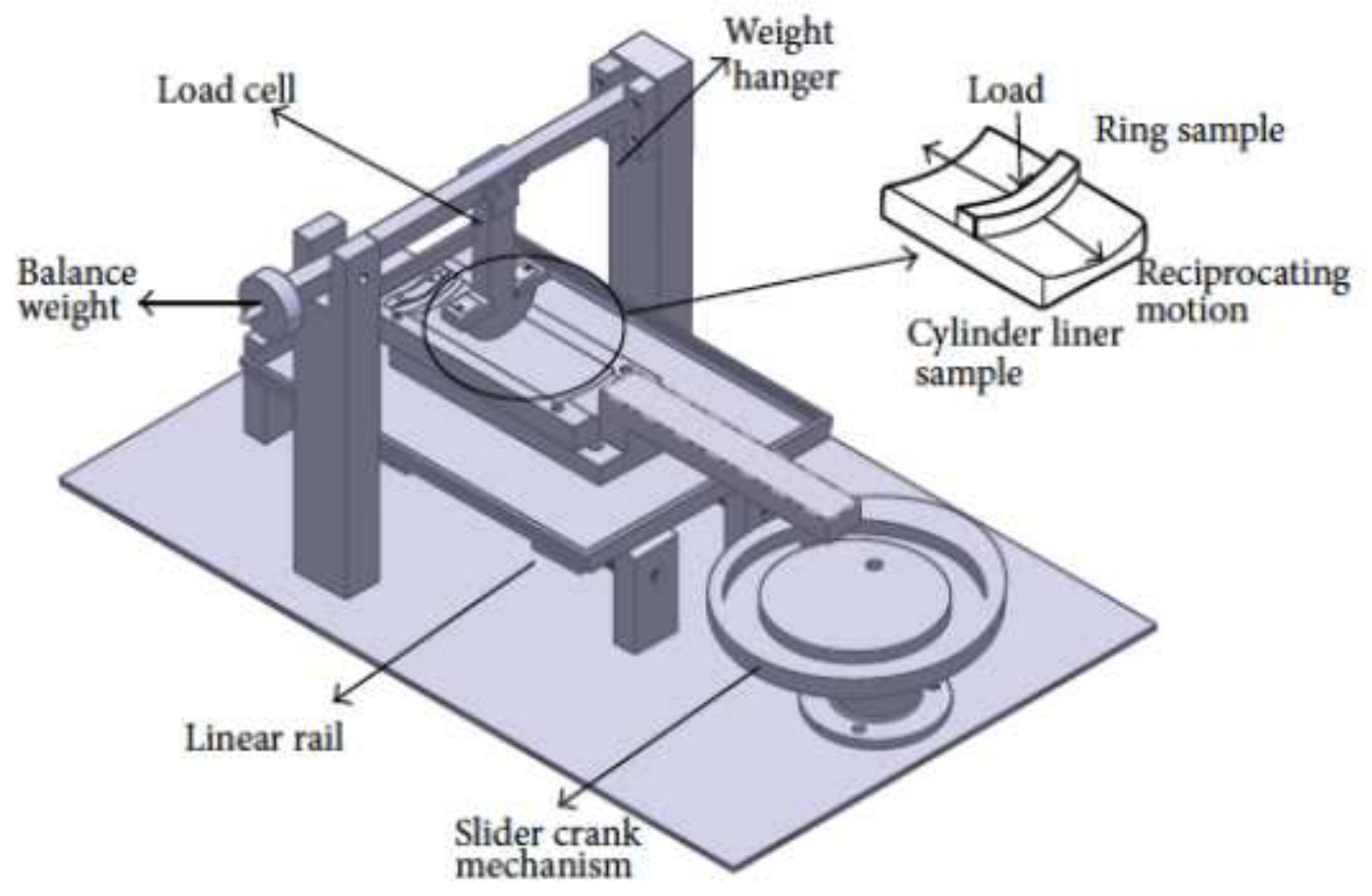

Figure 1

Piston ring reciprocating liner test machine, contact geometry, and test sample.

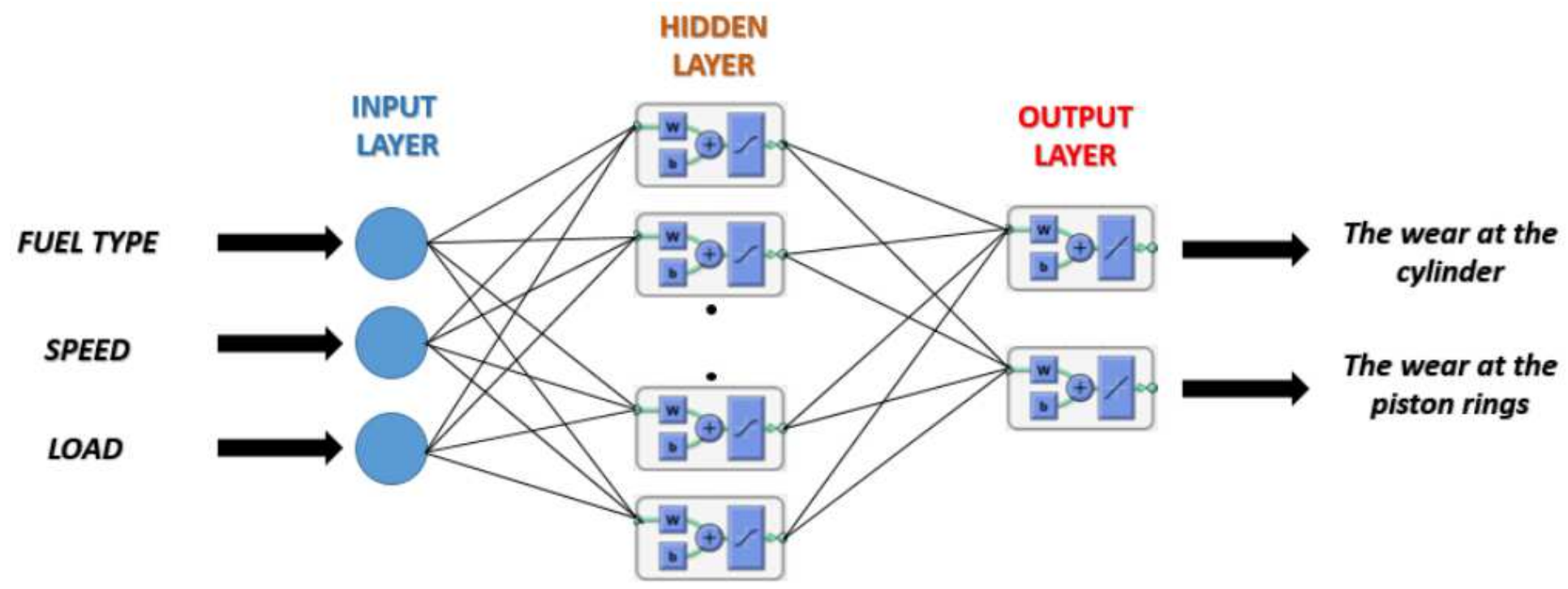

Figure 2

A Schematic structure of the artificial neural networks (ANNs) 

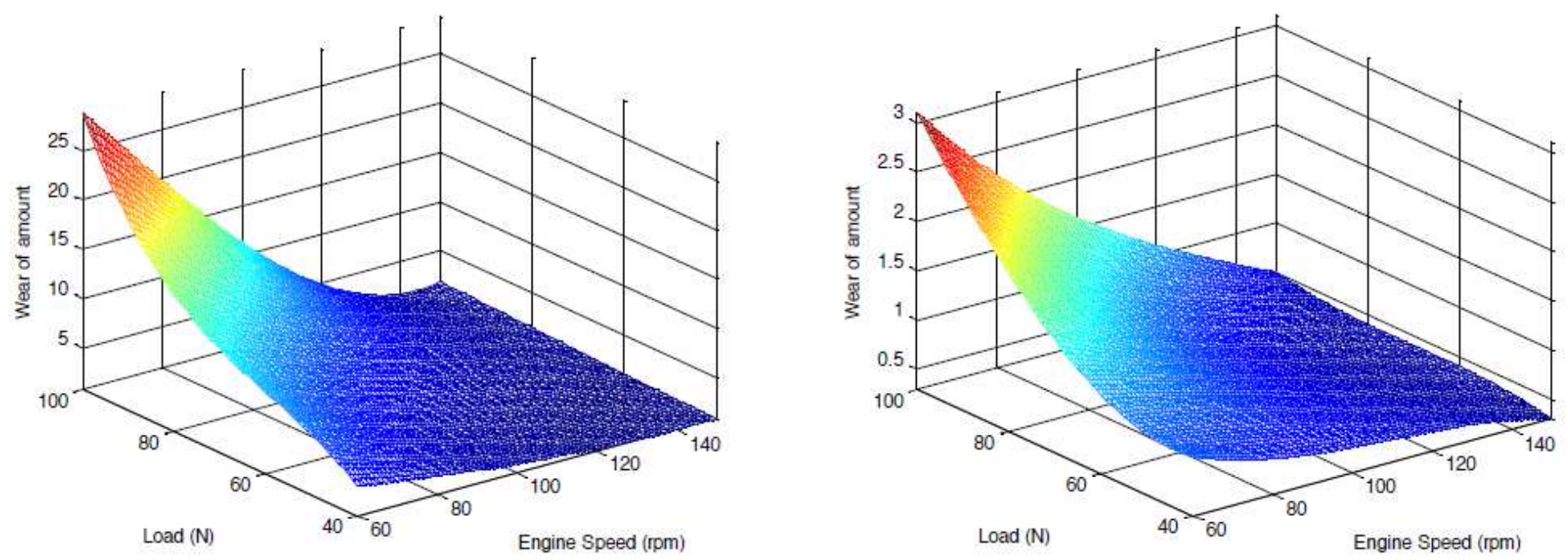

a)
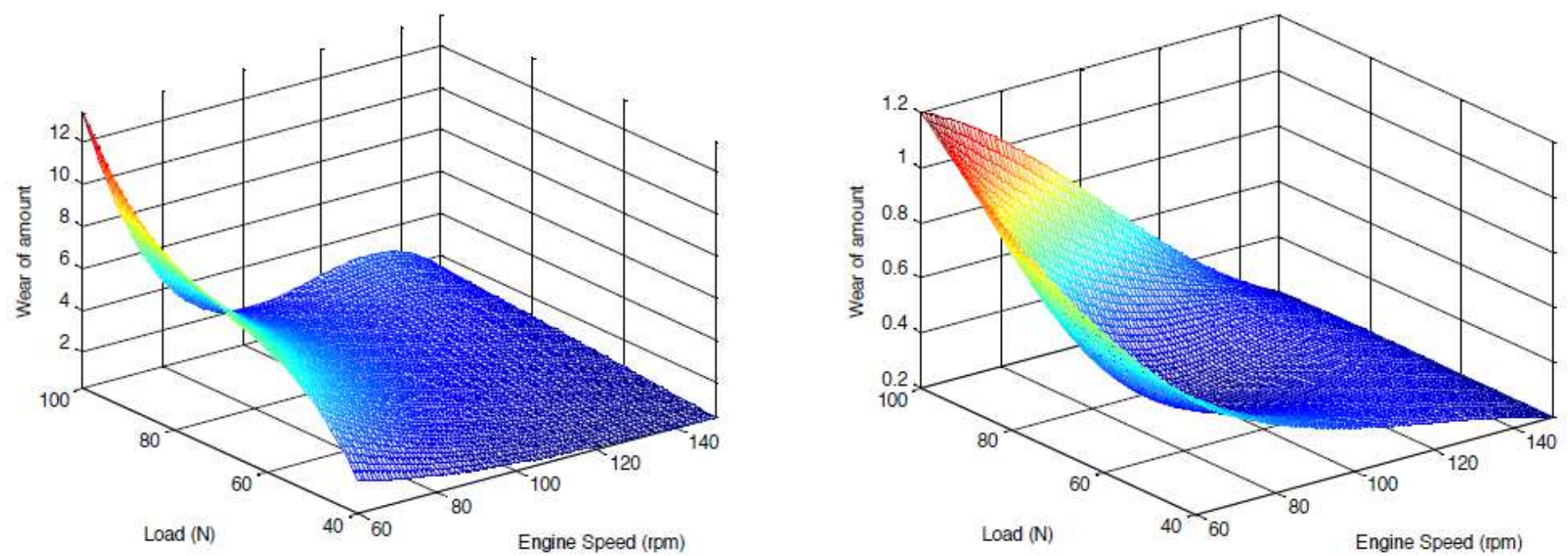

b)

Figure 3

Amount for wear at the cylinder and piston rings a) diesel fuels b) biodisel fuels 


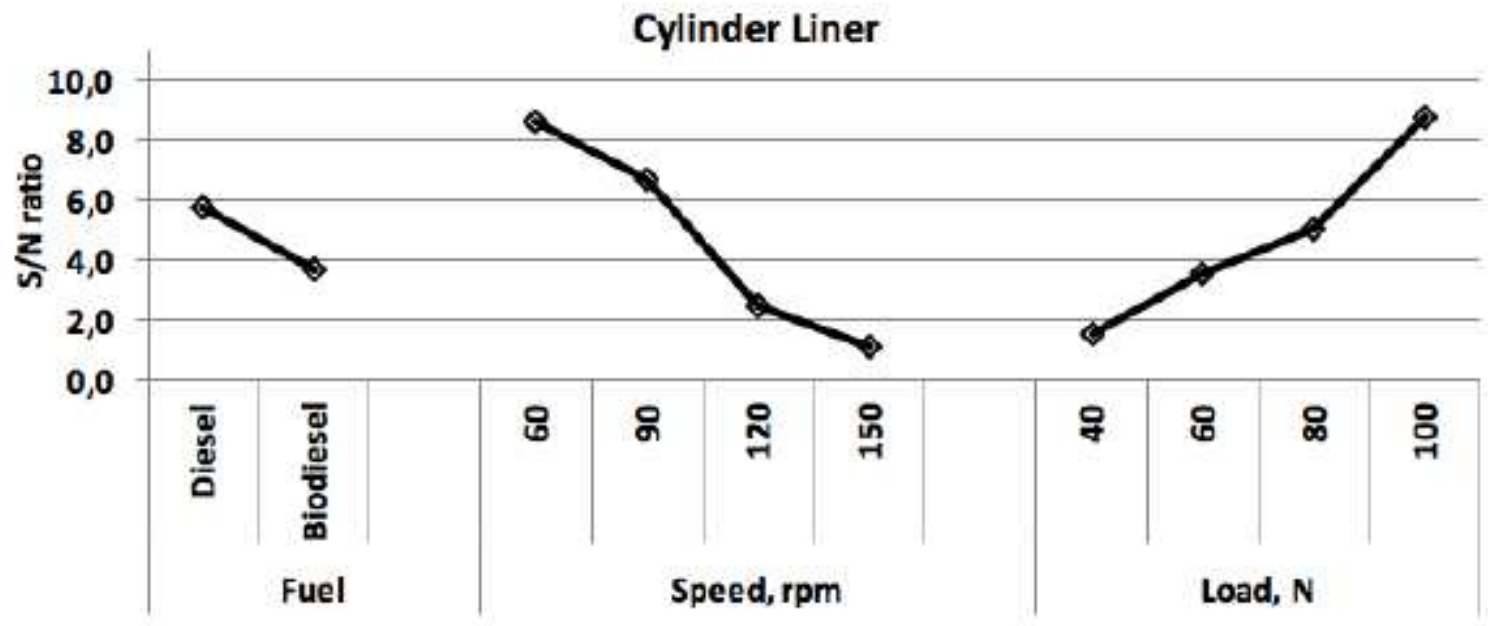

a)

Piston Ring

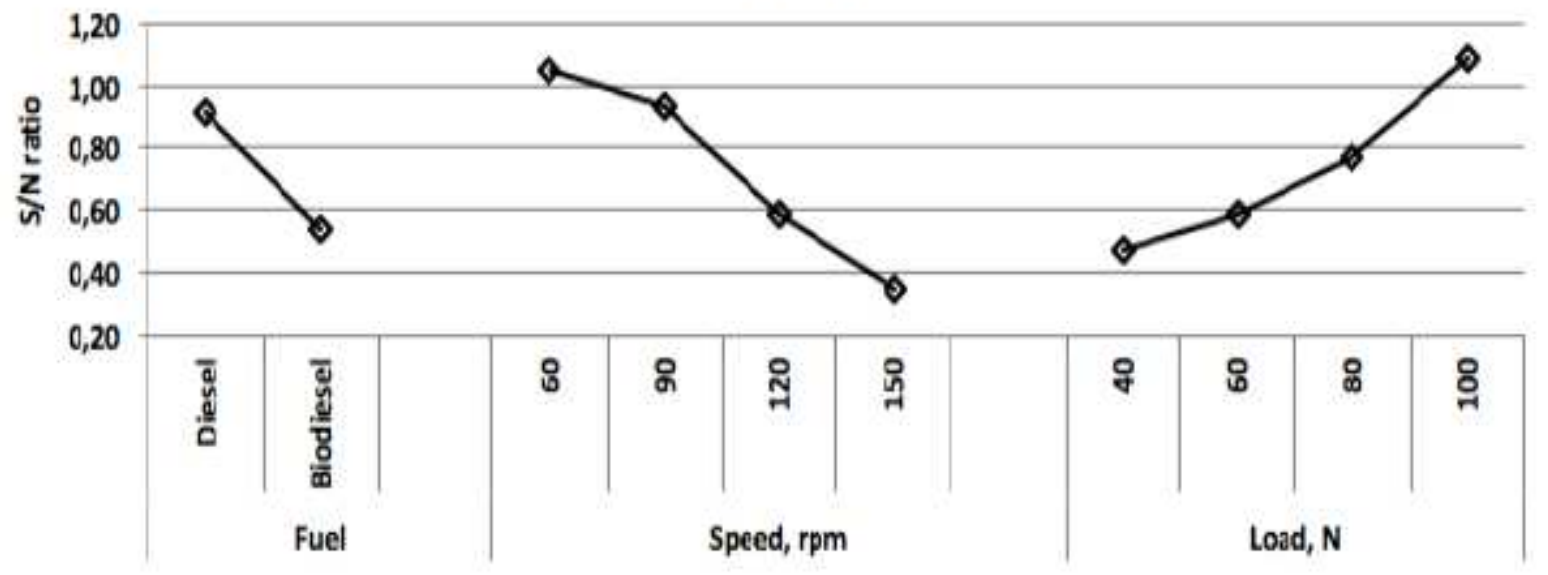

b)

Figure 4

$\mathrm{S} / \mathrm{N}$ values of factor levels at he wear, a) cylinder b) piston rings
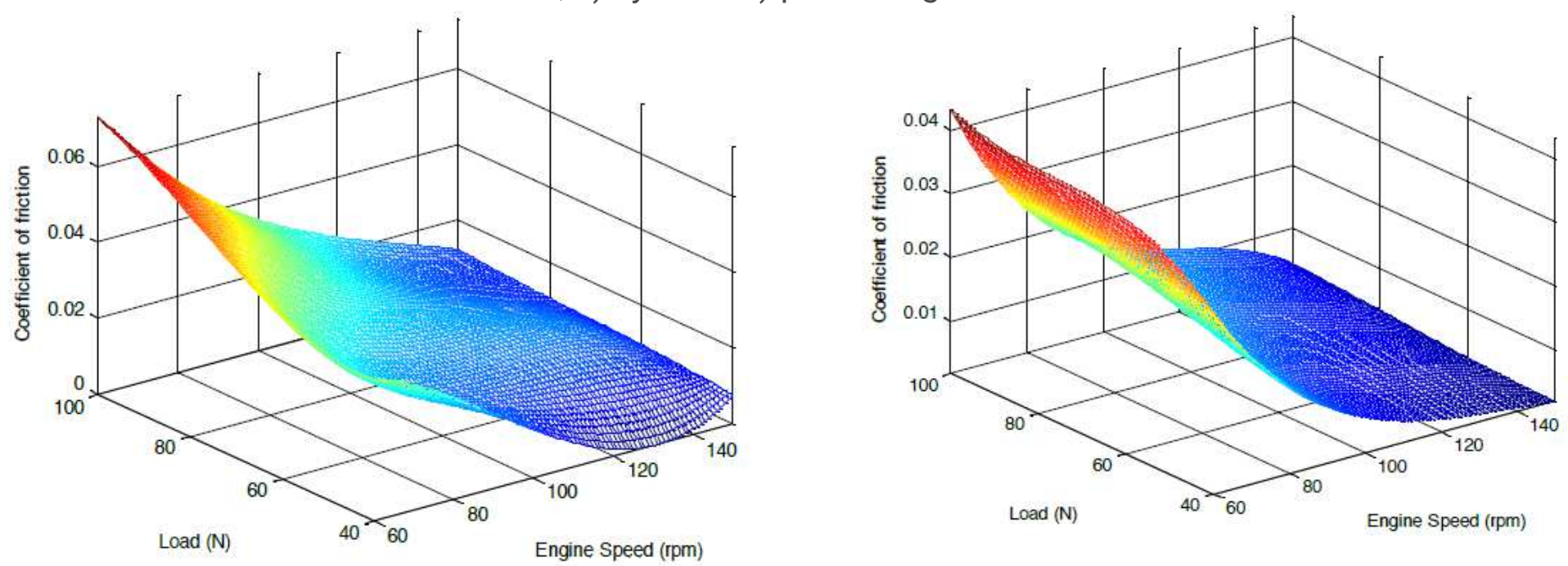
Figure 5

Variation of coefficient friction as diesel and biodiesel fuel at the among cylinder and piston rings

\section{Friction Coefficient}

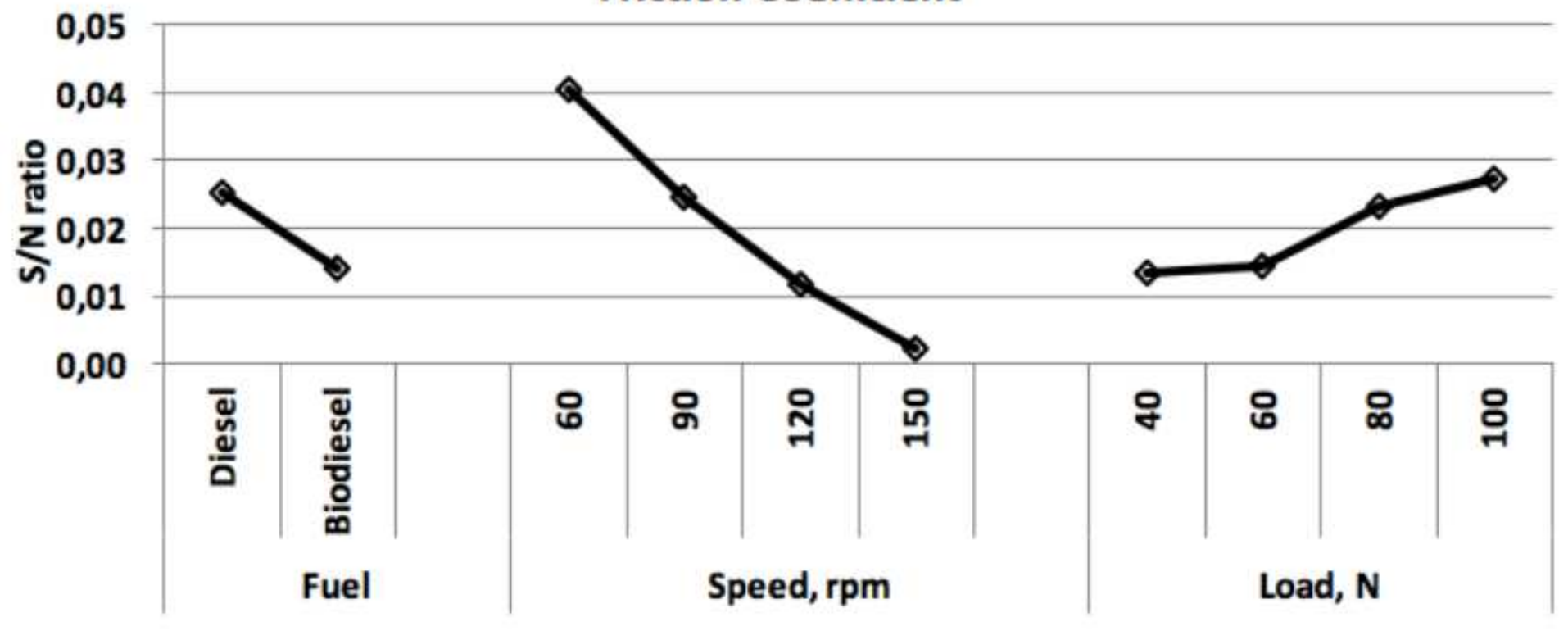

Figure 6

$\mathrm{S} / \mathrm{N}$ values of factor levels for friction coefficient 

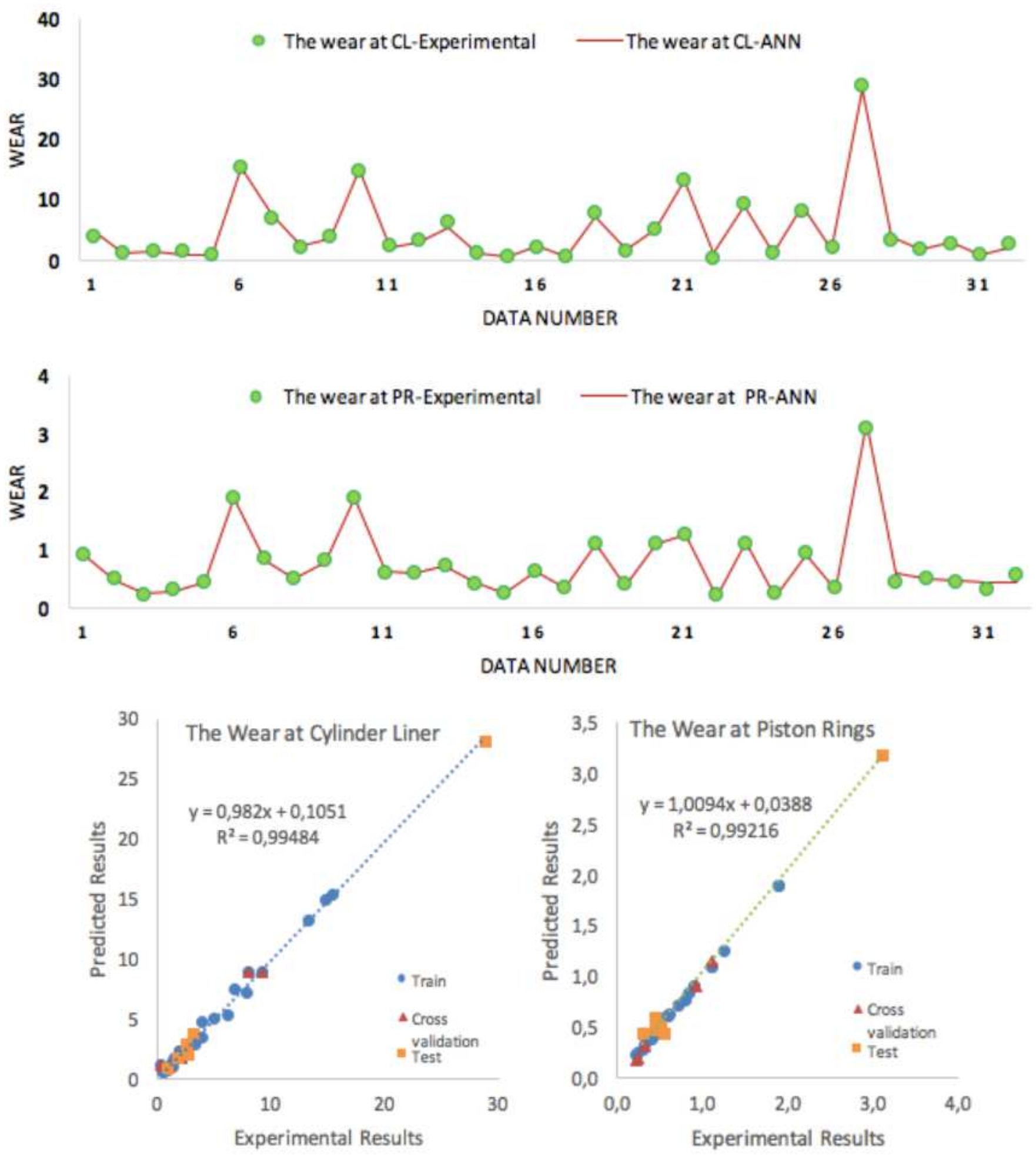

Figure 7

Experimental results versus ANN in terms of the wear at cylinder liner $(\mathrm{CL})$ and piston rings $(\mathrm{PR})$ 